\title{
Reduction of viable Mycobacterium avium ssp. paratuberculosis in slurry subjected to anaerobic digestion in biogas plants
}

\author{
K. Donat, ${ }^{1,2 *}$ S. W. F. Eisenberg, ${ }^{3}$ E. Einax, ${ }^{1}$ G. Reinhold, ${ }^{4}$ and V. Zoche-Golob ${ }^{1}$ \\ ${ }^{1}$ Animal Health Service, Thuringian Animal Diseases Fund, 07745 Jena, Thuringia, Germany \\ ${ }^{2}$ Clinic for Obstetrics, Gynecology and Andrology of Large and Small Animals with Veterinary Ambulance, Justus Liebig University Giessen, \\ 35392 Giessen, Germany \\ ${ }^{3}$ Animal Disease Fund of Lower Saxony, 30169 Hanover, Lower Saxony, Germany \\ ${ }^{4}$ Thuringian State Institute for Agriculture, 07745 Jena, Thuringia, Germany
}

\section{ABSTRACT}

Cattle infected with Mycobacterium avium ssp. paratuberculosis (MAP) shed the bacterium in their feces. This may lead to considerable concentrations of MAP in slurry, which has been postulated to contribute to MAP transmission when this slurry is used as fertilizer. For other bacterial species, anaerobic digestion has been shown to reduce bacterial load and to increase the safety of organic waste. Therefore, the objective of this study was to investigate the effects of anaerobic digestion in biogas plants on MAP survival in slurry from 16 dairy farms with a history of MAP infection. Presence of MAP was determined using MAP culture and a commercial MAP IS900 quantitative PCR (qPCR) applied on untreated slurry samples, slurry samples after primary fermentation, and digestate. Unfermented slurry samples from most enrolled farms tested positive for MAP, via both culture and qPCR. After the fermentation process, MAP could no longer be cultured in most samples, with the exception of 2 samples from farms where high numbers of MAP-shedding cows were kept at the time of sampling. A Bayesian binomial model predicted a probability of $93 \%$ for a MAP-negative culture result after fermentation. In most samples, MAP DNA was still detectable when using the IS900 qPCR. The probability of a negative result in $\mathrm{qPCR}$ was estimated to be $27 \%$. Results of this study indicate that subjecting MAP-positive slurry to anaerobic digestion in biogas plants leads to a reduction of viable MAP below the detection limit; however, MAP DNA remained detectable. It remains undetermined whether MAP DNA detected in fermentation products is a residue of MAP degradation or belongs to viable MAP below the detection limit or in a dormant state. In conclusion, subjecting MAP-positive slurry to anaerobic mesophilic digestion reduces viable MAP concentration below

Received November 2, 2018

Accepted March 21, 2019.

*Corresponding author: kdonat@thueringertierseuchenkasse.de the detection limit. The use of digestion products as fertilizer on pasture and agricultural soils instead of untreated slurry may therefore reduce the risk of MAP transmission.

Key words: Johne's disease, mesophilic digestion, environment, fecal culture

\section{INTRODUCTION}

Mycobacterium avium ssp. paratuberculosis (MAP) is an acid-fast, slow-growing, mycobactin-dependent bacterium with high environmental persistence due to its unique cell wall (Larsen et al., 1956; Whittington et al., 2004). This bacterium is the causative agent of paratuberculosis, or Johne's disease, in cattle and other ruminants (Lombard, 2011). All over the world, Johne's disease causes production losses among animals in the subclinical stage and wasting, pitting edema, and chronic diarrhea in the clinical stage. Fecal shedding of MAP increases as the disease progresses, and a high within-herd prevalence often results in a high environmental burden of MAP (Wolf et al., 2017).

Although MAP needs a host for replication, its ability to survive outside the host for a long period leads to environmental contamination with MAP in infected herds (Eisenberg et al., 2010; Donat et al., 2011; Lavers et al., 2013). Areas contaminated with manure and slurry harbor large numbers of MAP and can play an important role in bacterial transmission. Similarly, applying animal waste as fertilizer to agricultural soils may pose a risk for bacterial transmission (Fecteau et al., 2010; Salgado et al., 2011; Elliott et al., 2015). In contrast to well-fermented grass silage, in which the presence of MAP was reduced below the detection limit, poorly preserved silage with low lactic acid content and insufficient acidification has high MAP counts and thus presents an increased risk for disease transmission (Katayama et al., 2000).

Both aerobic and anaerobic digestion have been shown to reduce the bacterial load of slurry for different bacterial species, which is considered to increase 
biosecurity of slurry (Olsen et al., 1985; Plym-Forshell, 1995; Grewal et al., 2006). Available data describing the effects of anaerobic and aerobic digestion on MAP content in slurry and manure are scarce and conflicting (Olsen et al., 1985; Grewal et al., 2006; Slana et al., 2011; Mazzone et al., 2018). Studies by Olsen et al. (1985) and by Grewal et al. (2006) presented experimental data mimicking aerobic or anaerobic digestion under standardized laboratory conditions. The results of these studies indicate that a significant reduction of viable MAP could be achieved with higher temperatures enhancing the bactericidal effect, implying that thermophilic digestion is more effective than mesophilic digestion for reduction of MAP counts. Two other research groups studied the survival of MAP in a small number of mesophilic biogas plants (BP) under field conditions (Slana et al., 2011; Mazzone et al., 2018). Samples were collected at different stages of the digestion process and analyzed for the presence of MAP by culture and IS900 quantitative PCR (qPCR). Descriptive analysis of the published data indicated a decrease in the overall numbers of viable MAP in samples collected after a period of fermentation/digestion, compared with pre-treatment samples, especially when a 2-stage digestion system was used. The qPCR results corroborated these results, because the digestion process reduced the amount of MAP DNA identified by qPCR; small amounts of MAP DNA, however, remained continuously detectable (Slana et al., 2011). In conclusion, the published results were inconsistent, and samples of only 1 or $2 \mathrm{BP}$ were included. The number of sampled BP included in earlier studies is thus too small to assess the effectiveness of anaerobic digestion for MAP reduction.

The objective of the present study was to confirm the reduction of viable MAP in slurry subjected to anaerobic digestion, as indicated in previous studies. For this purpose, slurry from dairy herds with known history of MAP infection was analyzed by culture and qPCR, and results were expressed dichotomously, positive or negative. Samples were obtained before and after anaerobic digestion in on-site $\mathrm{BP}$, and the persistence of viable MAP and MAP DNA in slurry and digestate was studied.

\section{MATERIALS AND METHODS}

\section{Dairy Herds and Biogas Plants}

Dairy farms were recruited from those enrolled in the voluntary paratuberculosis control program in Thuringia, federal state of Germany (Donat, 2017). At the end of 2014, an on-site BP was in process in 24 out of 54 MAP-positive dairy farms participating in the program, and 16 producers agreed to participate in this study. Among other measures, the program included hygiene improvement, trade control, certification steps, and an annual herd screening of adult dairy cows for MAP by fecal culture. Sampling was performed either as a whole-herd sampling on one day each year or as a continuous scheme testing individual animals at the time of pregnancy testing, drying off, puerperal controls, or other management measures. For study purposes, we considered a herd MAP positive if at least one MAP shedder was identified during the 6 mo before BP sampling. For each herd sampling date, the population of cows at risk, the number of cows having a valid MAP test result, and the number and percentage of cows determined to be MAP positive were collected (Table 1). Study herds consisted largely of German Holstein cows, housed in freestalls and fed a corn and grass silage-based TMR supplemented with grain, soy extraction meal or rape cake, and minerals. The proportion of feed materials varied according to nutrient contents and seasonal availability.

The on-site BP included in this study all were owned by the dairy producers and used primarily slurry and manure from the corresponding herd as substrate. All fermentors were located in close proximity to the barn complex, allowing easy transport of slurry to the fermentor, although some BP had a slurry store in between. All BP were fed several times a day and were operated continuously, with an input of substrate equaling the digested material, to ensure a constantly high gas production process to fuel the gas engines that produce electricity. A rotating mixer homogenized the fresh biomass and the bacterial mass in all fermentors and ensured a constant fermentation temperature. Fermented substrate continuously flowed out of the fermentor into the storage tank before being used as fertilizer (Figure 1).

\section{Sample Collection}

Samples from all BP but one were collected on at least at 2 occasions, with the first sampling between March and July 2015 and the second between November 2015 and April 2016. Limited availability and accessibility of digestate at the end of the fermentation process led to a wide spread of sampling dates. For each BP, a sample of slurry was taken from the channel or sump before it entered the fermentor, and one sample was collected after fermentation. From BP 2, 7, and 13, a third set of samples were collected before and after fermentation. From BP 4, slurry samples were obtained on 2 additional occasions. Because of the variation in types and construction of BP, samples from the fermentor itself during the fermentation process were only collectable 


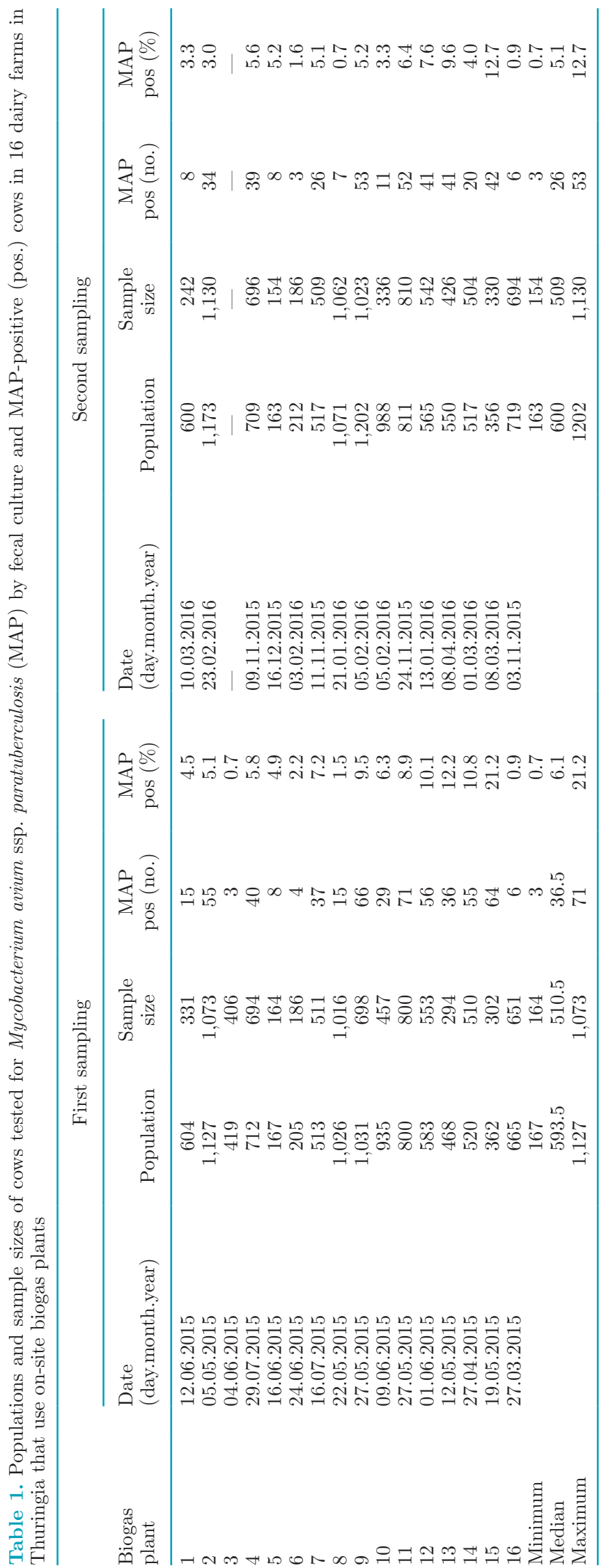

in 7 plants. Whenever possible, samples were collected using the technical equipment for sample collection from the runoff of the fermentor. A clean bucket was filled with approximately $5 \mathrm{~L}$ of material and stirred. At least $100 \mathrm{~mL}$ of material was decanted into a sterile 125-mL plastic cup with screw cap. Samples from the sump or the slurry channel were obtained using a small bucket attached to a rod (2 to $3 \mathrm{~m}$ in length), until 5 $\mathrm{L}$ were collected in a clean bucket. The same approach was used to collect digestate from the curing phase or final storage. The results of 1 additional sampling each in 3 herds, and 2 additional samplings in 1 herd, were included in the data analysis.

\section{Cultivation and Identification of Isolates}

All biomass samples were cultured according to the official manual of diagnostic procedures published by the Friedrich-Loeffler-Institut, the German Federal Research Institute for Animal Health (Friedrich-LoefflerInstitut, 2015). Briefly, for decontamination, $3 \mathrm{~g}$ of slurry or digestate was mixed with $30 \mathrm{~mL}$ of a $0.75 \%$ hexadecyl pyridinium chloride solution (Acros Organics, Fisher Scientific GmbH, Nidderau, Germany). After sedimentation of coarse material, approximately 20 $\mathrm{mL}$ of the supernatant was decanted and incubated at room temperature for 24 to $72 \mathrm{~h}$. After discarding the supernatant, we inoculated $0.2 \mathrm{~mL}$ of the sediment onto a commercial Herrold's egg yolk culture medium with Mycobactin J (Becton Dickinson GmbH, Heidelberg, Germany). After incubation under aerobic conditions at $37^{\circ} \mathrm{C}$ for $7 \mathrm{~d}$, culture tubes were sealed airtightly, cultivated for another 11 to $15 \mathrm{wk}$, and examined for mycobacterial growth every 2 wk. Differentiation of characteristic colonies was carried out by Ziehl-Neelsen staining and a conventional IS900 qPCR (Englund et al., 1999). Samples with typical colonies, acid-fast bacteria in the Ziehl-Neelsen staining, or a positive IS900 qPCR were characterized as MAP culture positive.

\section{Identification of MAP DNA}

We extracted MAP DNA from biomass samples using a commercial nucleic acid isolation kit (QIAamp DNA Mini Kit, Qiagen GmbH, Hilden, Germany) after preconcentration of samples using an Adiafilter (Adifil 100, Adiagène, Saint Brieuc, France) as described by Donat et al. (2016). Using the filter system, bacteria present in the $10 \mathrm{~mL}$ of fecal supernatant were concentrated by centrifiltration, enabling an increase in the sensitivity of the qPCR method in general. A commercially available IS900-based qPCR protocol (Adiavet Paratb, Adiagène) was applied to detect MAP DNA. The qPCR kit was used as described by Donaghy et 
al. (2008). A sample was considered positive for MAP DNA if cycle threshold values were below 38.0, and inconclusive if cycle threshold values were between 38.0 and 40.0. If the signal of the internal amplification control did not meet the reference range, the $\mathrm{qPCR}$ result was rated as inconclusive.

\section{Data Analysis}

To evaluate a possible relationship between the frequencies of MAP-positive slurry samples before and after fermentation for each BP, Bayesian binomial models were used. Separate models for the cultivation of MAP isolates and for the isolation of MAP DNA were fitted. The number of MAP-positive samples after fermentation from each BP, $Y_{i}$, was assumed to be binomially distributed:

$$
\begin{aligned}
Y_{i} & \sim \operatorname{Bin}\left(\text { Pneg }_{i}, \text { nPostSamples }_{i}\right), \\
\operatorname{logit}\left(\text { Pneg }_{i}\right) & =\beta_{0}+\beta_{1} \times \text { PreSamplesNeg }_{i},
\end{aligned}
$$

with Pneg $_{i}$ the probability of a slurry sample after fermentation from BP $i$ being MAP negative, $n$ PostSamples $_{i}$ the total number of samples after fermentation from BP $i$, and PreSamplesNeg the $_{i}$ ln of the percentage of MAP-negative samples before fermentation from $\mathrm{BP} i$, centered and divided by 2 standard deviations (Gelman, 2008). To allow ln transformation of variables that contained zeros as values, a constant was added to all values before transformation. An approximation of the $2.5 \%$ quantile, under the assumption of a lognormal distribution, was used as constant:

$$
\frac{q_{0.5}(\text { values })}{\left[q_{0.5}(\text { values }) / q_{0.25}(\text { values })\right]^{2.9}},
$$

where $q_{0.5}$ and $q_{0.25}$ were the 50 and $25 \%$ quantiles, respectively.

Cauchy distributions with center 0 and scale 2.5 were applied as priors for the regression coefficients $\beta_{0}$ and $\beta_{1}$ as described by Gelman et al. (2008). The model was rerun with center 5 for the prior distribution of $\beta_{1}$, to assess the influence of the chosen prior on the conclusions inferred from the parameter estimates. The model parameters were estimated using Markov chain Monte Carlo and Gibbs sampling. The sampling was performed in JAGS version 4.2.0 (Plummer, 2016) via $\mathrm{R}$ version 3.3.1 (R Core Team, 2016). Four sampling chains with different initial values were run for 40,000 steps after a burn-in period of 10,000 steps. After thinning, 200 samples remained in each chain. Convergence was assessed using trace plots and the Brooks-GelmanRubin diagnostic.

The probability of a sample after fermentation being MAP negative would depend on the frequency of MAP-negative samples before fermentation of a BP, if the $95 \%$ highest posterior density interval of $\beta_{1}$ excluded 0 . If the $95 \%$ highest posterior density interval of $\beta_{1}$ did not exclude 0 and the model including $\beta_{1} \times$

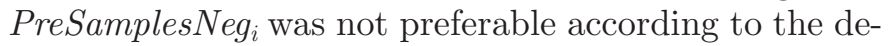
viance information criterion (Spiegelhalter et al., 2002), a reduced model without $\beta_{1} \times$ PreSamplesNeg ${ }_{i}$ would be used to predict the probability of a sample after fermentation being MAP negative.

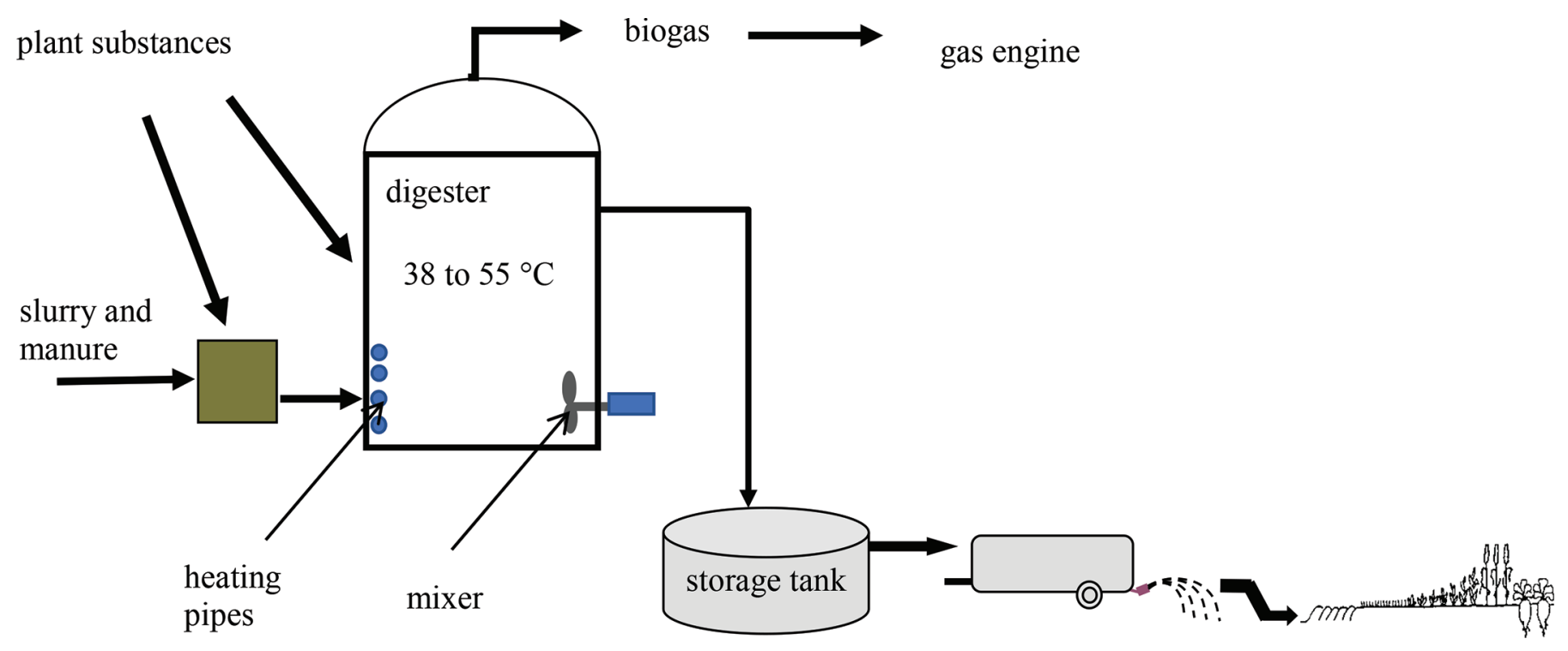

Figure 1. Diagram of the substance flow in an on-farm biogas plant. 


\section{RESULTS}

\section{Dairy Herds and Biogas Plants}

Sampling dates, herd size at the time of BP sampling, number of cows having a valid test result, and number and percentage of cows having a MAP-positive test result at the time of $\mathrm{BP}$ sampling are summarized in Table 1 . In the 16 study farms (Table 2), slurry undergoing digestion primarily originated from dairy cows (all farms), young stock (12 farms), and fattening bulls (2 farms).

The percentage of slurry and manure from cattle ranged between 36 and $98 \%$ (median: 79\%). Plant substrates such as corn or grass silage, cereals, orts, and other organic material were added to all fermentors in different proportions. Biogas plants 4, 5, 9, and 13 used additional manure from pigs, sheep, or laying hens.

All fermentors were mesophilic, with a mean fermentation time of 41 to $213 \mathrm{~d}$ (median: $78.5 \mathrm{~d}$ ). The fermentation temperature ranged between 39 and $45^{\circ} \mathrm{C}$, and the temperature during final composting after fermentation ranged between 35 and $45^{\circ} \mathrm{C}$ (Table 2).

\section{MAP Detection}

Detailed results of MAP testing for each BP are given in Table 3. For all organic matter samples collected before, during, and after fermentation, a valid result of bacteriological culture was available. Of the 36 slurry samples collected before fermentation, 18 (50\%) showed a MAP-positive result, whereas only 3 of the 16 samples (19\%) that were collected directly from the fermentor and 2 of 30 samples (7\%) of digestate collected after fermentation were MAP culture positive.

When qPCR was performed on slurry samples before fermentation, 21 of the 36 samples (58\%) tested positive, $3(8 \%)$ were considered suspicious, and $10(28 \%)$ were negative for MAP DNA. Similarly, after fermentation, MAP DNA was detected in 17 of 30 samples $(56 \%)$ of digestate; only 8 samples $(27 \%)$ tested negative, and $3(10 \%)$ showed an inconclusive test result. During fermentation, the proportion of qPCR-positive samples was $75 \%$. Inconclusive qPCR results were obtained from 2 of the 36 samples before, 2 of 30 after, and 1 out of 16 during fermentation. Figure 2 summarizes the proportions of negative and nonnegative results for both detection methods.

For $6 \mathrm{BP}(2,3,5,7,11,16)$ all samples obtained before, during, and after fermentation were culture negative. In the $2 \mathrm{BP}$ where MAP was cultured from the digestate after fermentation, a high number and percentage of MAP shedders (BP $4: \mathrm{n}=39$, or $5.6 \%$; BP 13: $\mathrm{n}=41,9.6 \%$ ) were kept on the premises at time of sampling.
Of the $6 \mathrm{BP}$ that were found culture negative before, during, and after fermentation, only BP 3 was also qPCR negative at all sampling points; BP 5 achieved an inconclusive result, and the other $4 \mathrm{BP}$ were positive on qPCR at one of the sampling points. In $\mathrm{BP} 4$ all samples were negative for MAP DNA, although MAP was cultured from that BP. For 2 culture-positive BP (6 and 14), a reduction in the proportion of qPCR-positive samples was observed when results of digestate were compared with those from the slurry. In the remaining 7 BP, MAP DNA was detected in all samples collected before, during, and after fermentation.

Additional samples taken in BP 2, 4, 7, and 13 showed similar results when compared with the first and second sampling event. In BP 2 and 4, the additional slurry samples were negative in culture and qPCR. For BP 7 , all samples were positive in $\mathrm{qPCR}$ but yielded negative culture results. Completely positive qPCR results were achieved in BP 13, but all samples collected before fermentation and one after were MAP-positive in culture.

\section{Bayesian Binomial Model}

Due to sampling difficulties in 2 BP after fermentation, only 14 BP (Table 3 ) were included in the model to estimate the probability of getting a negative test result in a sample from digestate after fermentation of slurry from MAP-positive dairy herds in an on-site BP. We found no influence of the frequency of MAP-negative slurry samples before fermentation on the probability of a negative sample after fermentation, using either the culture or the $\mathrm{qPCR}$ model. Even using a prior distribution with center 5 for the parameter did not change this result.

When culture was used, the median probability for a negative test result after fermentation was $93.0 \%$ (95\% highest posterior density interval: 83.6 to $99.5 \%$ ). When using detection of MAP DNA by qPCR, a probability of $27.1 \%$ (95\% highest posterior density interval: 12.8 to $43.1 \%$ ) for a negative test result was predicted.

\section{DISCUSSION}

Slurry from MAP-positive farms is known to contain large numbers of MAP and is therefore considered a risk factor for MAP transmission when used as a fertilizer on pastures and for crop production (Fecteau et al., 2010; Salgado et al., 2011). Anaerobic digestion reduces the overall bacterial load of slurry (Olsen and Larsen, 1987). Studies specifically exploring the suitability of anaerobic digestion for reduction of MAP have been promising so far but are based on small case numbers only (Slana et al., 2011; Mazzone et al., 2018). To the best of our knowledge, this is the first study explor- 
DONAT ET AL.

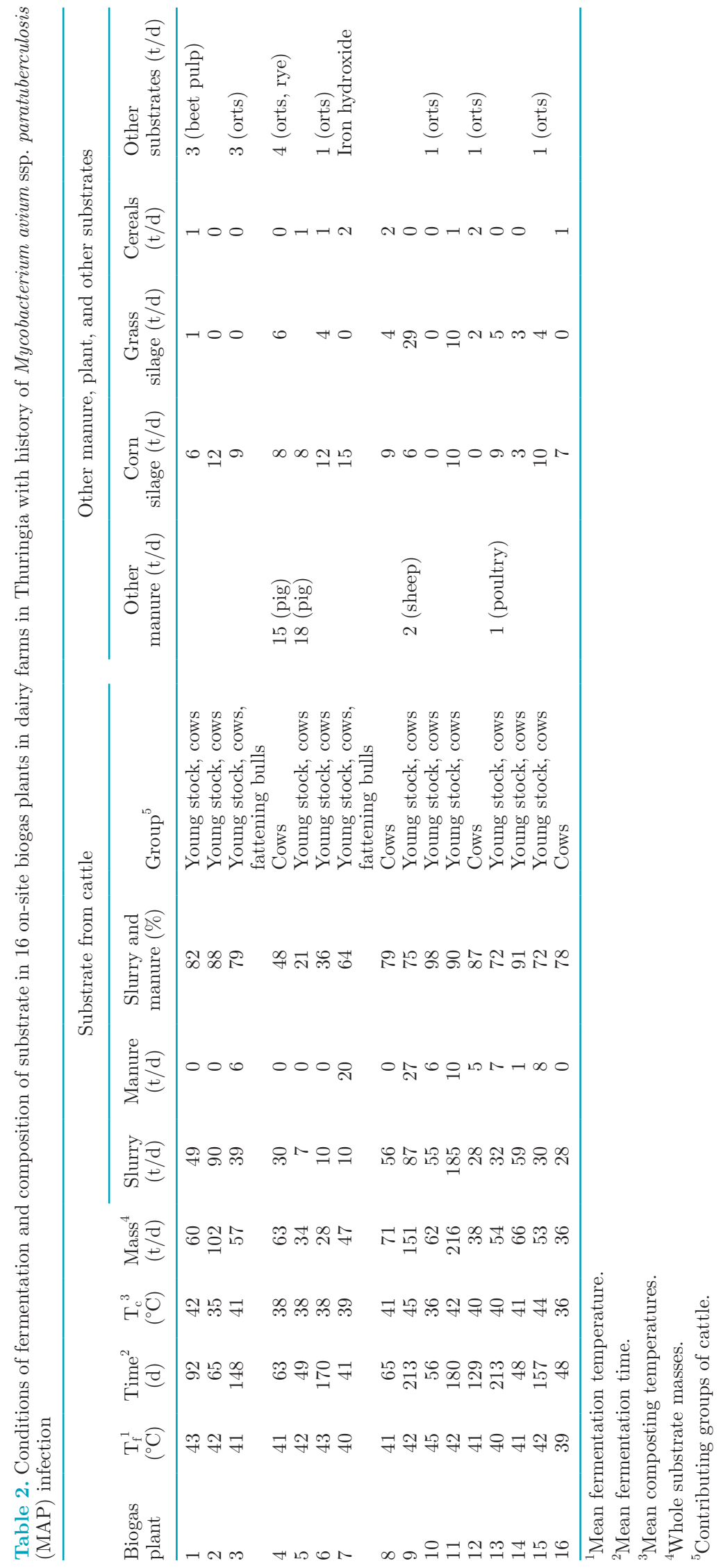


Table 3. Detection of Mycobacterium avium ssp. paratuberculosis (MAP) by fecal culture and MAP DNA by quantitative $\mathrm{PCR}(\mathrm{qPCR})$ in slurry from dairy cows before fermentation, and digestate during and after fermentation, in on-farm biogas plants in 16 MAP-positive dairy farms in Thuringia

Number of slurry samples

(MAP positive, suspicious, or inconclusive/MAP negative)

\begin{tabular}{|c|c|c|c|c|c|c|}
\hline \multirow{2}{*}{$\begin{array}{l}\text { Biogas } \\
\text { plant }\end{array}$} & \multicolumn{3}{|c|}{ Culture } & \multicolumn{3}{|c|}{ qPCR } \\
\hline & Before & During & After & Before & During & After \\
\hline 1 & $2(2 / 0)$ & & $2(0 / 2)$ & $2(2 / 0)$ & & $2(2 / 0)$ \\
\hline 2 & $3(0 / 3)$ & & $2(0 / 2)$ & $3(1 / 2)$ & & $2(2 / 0)$ \\
\hline 3 & $1(0 / 1)$ & & $1(0 / 1)$ & $1(0 / 1)$ & & $1(0 / 1)$ \\
\hline 4 & $4(2 / 2)$ & $2(1 / 1)$ & $2(1 / 1)$ & $4(0 / 4)$ & $2(0 / 2)$ & $2(0 / 1)$ \\
\hline $5^{1}$ & $2(0 / 2)$ & $2(0 / 2)$ & & $2(0 / 2)$ & $2(1 / 1)$ & \\
\hline 6 & $2(1 / 1)$ & $2(1 / 1)$ & $3(0 / 3)$ & $2(2 / 0)$ & $2(1 / 1)$ & $3(1 / 2)$ \\
\hline 7 & $3(0 / 3)$ & $6(0 / 6)$ & $3(0 / 3)$ & $3(3 / 0)$ & $6(6 / 0)$ & $3(3 / 0)$ \\
\hline 8 & $2(1 / 1)$ & $1(0 / 1)$ & $1(0 / 1)$ & $2(2 / 0)$ & $1(1 / 0)$ & $1(1 / 0)$ \\
\hline 9 & $2(2 / 0)$ & & $2(0 / 2)$ & $2(2 / 0)$ & & $2(2 / 0)$ \\
\hline 10 & $2(2 / 0)$ & & $2(0 / 2)$ & $2(2 / 0)$ & & $2(2 / 0)$ \\
\hline 11 & $2(0 / 2)$ & & $4(0 / 4)$ & $2(2 / 0)$ & & $4(2 / 2)$ \\
\hline 12 & $2(2 / 0)$ & $1(1 / 0)$ & $1(0 / 1)$ & $2(2 / 0)$ & $1(1 / 0)$ & $1(1 / 0)$ \\
\hline 13 & $3(3 / 0)$ & & $3(1 / 2)$ & $3(3 / 0)$ & & $3(3 / 0)$ \\
\hline 14 & $2(1 / 1)$ & & $2(0 / 2)$ & $2(2 / 0)$ & & $2(1 / 1)$ \\
\hline $15^{1}$ & $2(2 / 0)$ & $2(0 / 2)$ & & $2(2 / 0)$ & $2(2 / 0)$ & \\
\hline 16 & $2(0 / 2)$ & & $2(0 / 2)$ & $2(1 / 1)$ & & $2(1 / 1)$ \\
\hline
\end{tabular}

${ }^{1}$ Biogas plants 5 and 15 were not included in statistical analysis due to sampling difficulties after fermentation caused by the construction of the fermenter and of the runoff to the storage of digestate.

ing the suitability of anaerobic digestion of slurry from MAP-positive herds for the reduction of viable MAP below the detection limit under field conditions on a larger scale.

Because MAP is primarily excreted in feces, slurry and manure from adult cattle are considered high-risk organic materials with respect to MAP transmission (Doré et al., 2012). This was confirmed by the isolation of MAP from grass that germinated through feces from MAP-positive sheep for up to $24 \mathrm{wk}$ and from positive cattle up to 16 wk (Whittington et al., 2004; Eppleston et al., 2014). Using slurry or manure as organic fertilizer on agricultural soils is considered a risk factor for bacterial transmission by pasturing or reintroduction of the infectious agent by feedstuff such as grass silage or hay (Pribylova et al., 2011; Salgado et al., 2011; Fecteau et al., 2013; Elliott et al., 2015). The German Federal Ministry for Food and Agriculture advised producers to apply slurry and manure from MAP-positive herds only on cropland, not on pastures (Federal Ministry for Food and Agriculture, 2014). So far, results of several studies (Salgado et al., 2011; Elliott et al., 2015) and official regulations take into account that unfermented animal waste from MAP-positive herds poses a possible risk when applied to pastures. A procedure to reduce MAP contamination in slurry would be a valuable tool for producers in their efforts to reduce the environmental burden of MAP.

In Germany, a growing proportion of dairy farms run on-site BP. New legislation on renewable energies has accelerated this development over the last 2 decades (Federal Diet, 2000). Slurry or manure from cattle was fermented in 168 of the $230 \mathrm{BP}$ in Thuringia, indicating that a high proportion of the commercial dairy farms in Thuringia mainly process manure in on-site BP. The percentage of fermented substrates processed in BP was estimated to consist of $70 \%$ slurry, of which $87 \%$ originated from cattle (Reinhold, 2017). Most Thuringian $\mathrm{BP}$ are mesophilic fermentors. Determining the effectiveness of these BP for the reduction of viable MAP is critical for the local dairy industry. Therefore, farms enrolled in this study were exclusively operating BP employing mesophilic fermentation, with a temperature range between 39 and $45^{\circ} \mathrm{C}$.

So far, the effects of anaerobic fermentation have been studied in a laboratory setting and in 2 smallscale studies on MAP reduction, conducted in 1 or 2 mesophilic BP, where a significant decline of MAP counts in digestate was reported (Slana et al., 2011; Mazzone et al., 2018). Our data are in agreement with these findings, showing that subjecting MAP-positive slurry to mesophilic fermentation reduces viable MAP below the detection limit in most $\mathrm{BP}$, resulting in a $93 \%$ probability of a negative result in bacteriological cultivation.

In the present study, however, MAP was still cultured from 2 digestate samples originating from herds with a high within-herd prevalence of MAP shedders. This indicates that in cases of high initial MAP burden, not all viable MAP is eliminated from the organic matter. In 
those cases, the routine fermentation process does not render the digestate completely free from MAP. Similar findings were reported in the study by Mazzone et al. (2018), where MAP was never cultivated from the final digestate after fermentation in a double-stage BP using 2 fermentors consecutively, but was cultivated sporadically from the digestate of a single-stage BP. These results suggest that differences in type of BP may affect the fermentation process, and the initial MAP burden of the substrate might influence the outcome of the fermentation process as far as MAP decontamination is concerned. Although the $16 \mathrm{BP}$ included in the present study used a variety of substrates (Table 2) and varied considerably in construction type, in all $\mathrm{BP}$ we identified a reduction of viable MAP in fermented slurry.

Survival of MAP in slurry has also been shown to be negatively correlated with temperature, incubation time, and DM content (Jørgensen, 1977; Olsen et al., 1985; Grewal et al., 2006). Although MAP can tolerate temperatures up to $73^{\circ} \mathrm{C}$ for 15 and $25 \mathrm{~s}$ (Grant et al., 2002), biogas fermentation probably provides complex interactions between micro-organisms and competitive environmental conditions. Survival times for MAP after incubation in cattle slurry ranged from $252 \mathrm{~d}$ at $5^{\circ} \mathrm{C}$ to $98 \mathrm{~d}$ at $15^{\circ} \mathrm{C}$ (Jørgensen, 1977). In a laboratory setting Olsen et al. (1985) were able to re-isolate MAP from mesophilic biogas plants at d 21 but not at d 28, whereas at thermophilic conditions $\left(53\right.$ to $\left.55^{\circ} \mathrm{C}\right) \mathrm{MAP}$ was already undetectable within $1 \mathrm{~d}$. For all BP enrolled in our study, a fermentation time between 41 and $213 \mathrm{~d}$ was calculated. Because fermentation time is a significant factor, digestion in a gas-tight fermentor for at least $150 \mathrm{~d}$ has been mandated by law for all BP constructed in Germany since 2009 (Federal Diet, 2011). Furthermore, BP operators are required to have storage capacity for digestate for at least $180 \mathrm{~d}$, which assures a sustainable composting process (Federal Diet, 2011). Grewal et al. (2006) identified the role of dry matter on

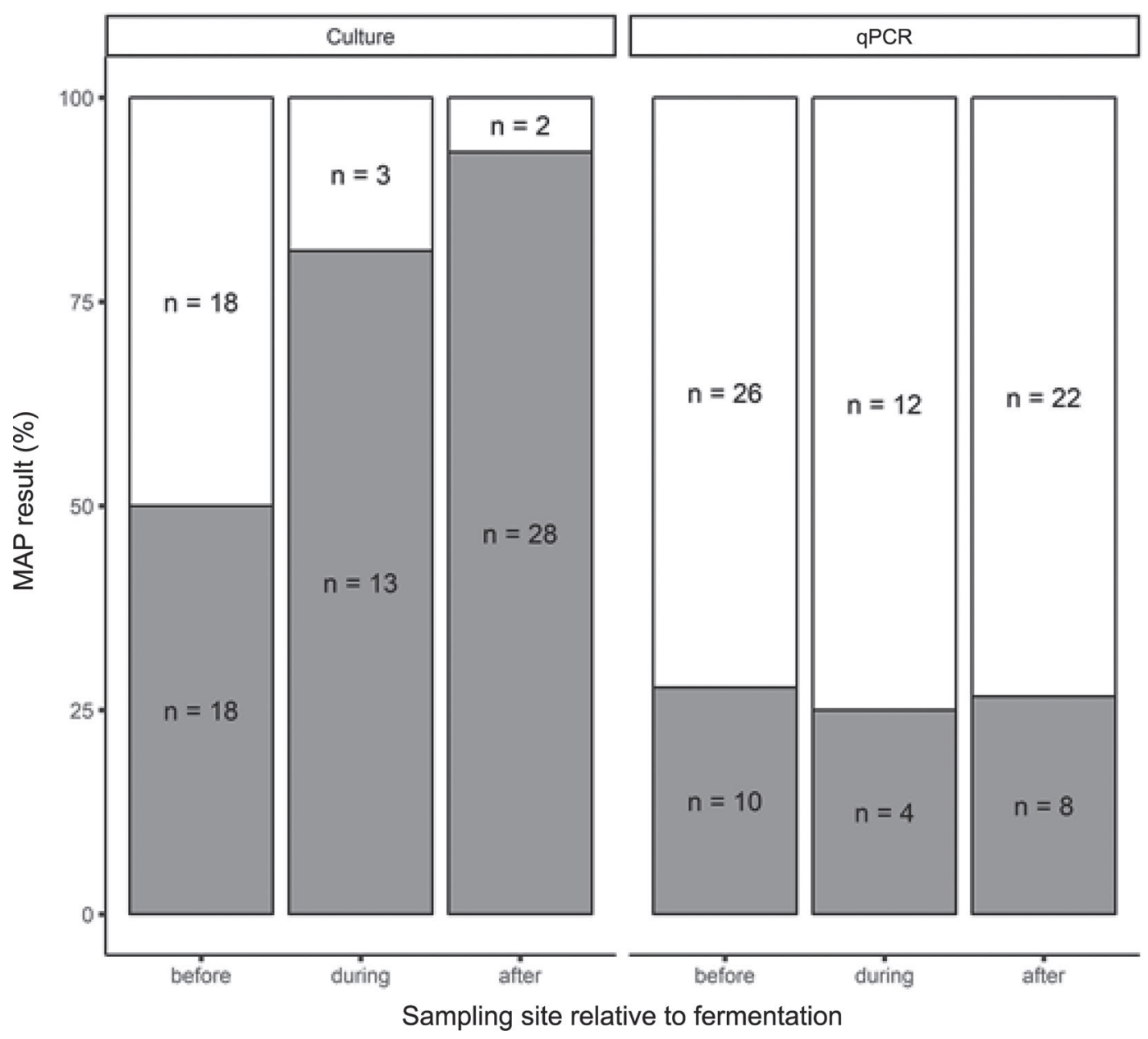

Figure 2. Proportions of negative (gray) and non-negative (white) results of tests for Mycobacterium avium ssp. paratuberculosis (MAP) by fecal culture and MAP DNA by quantitative PCR (qPCR) in slurry from dairy cows before fermentation, and digestate during and after fermentation, in on-farm biogas plants in 16 MAP-positive dairy farms in Thuringia. 
MAP survival, where a longer storage period was required to eliminate MAP from liquid manure compared with composted or pack-stored manure, where MAP was not detectable by culture after $3 \mathrm{~d}$ (Grewal et al., 2006). In summary, earlier findings support our finding that mesophilic fermentation leads to a substantial reduction of viable MAP in slurry when fermentation time is considered and sufficiently long.

Several studies regarding MAP culture suggest that solid culture is less sensitive than liquid (Collins et al., 1990; Whittington et al., 1998; Pozzato et al., 2011). Therefore, the use of a solid culture medium to detect the presence of viable MAP might be considered a weakness of the present study. Nonetheless, because $50 \%$ of samples collected before fermentation were MAP culture positive, the method used in this study was able to show a clear decrease in viable MAP-positive samples. Therefore, the conclusion that anaerobic degradation reduces viable MAP in slurry remains valid, although a liquid culture technique might have detected more mycobacteria in some cases.

In contrast to the results of MAP culture, MAP DNA was detected in most samples of slurry and digestate, indicating that fermentation did not lead to complete degradation. This finding is in agreement with other experimental (Grewal et al., 2006) and field studies (Slana et al., 2011) and was consistently reproduced in most BP included in the present study. A reduction in the proportion of qPCR-positive samples was observed in $2 \mathrm{BP}$, but some samples were qPCR positive even there. We cannot differentiate whether the MAP DNA detected in the fermentation products is only a degradation product of MAP or whether it belonged to viable MAP, which may have been below the detection limit of the culture technique used, or to MAP in a dormant state. On the one hand, an increasing ammonia concentration due to bacterial fermentation could have led to MAP degradation, as it was observed in ammonia-treated silages (Katayama et al., 2001). On the other hand, Australian authors have proposed that MAP may enter a dormant or viable-nonculturable state, permitting survival of the bacterium without requiring replication (Whittington et al., 2004). Dormancy is induced by unfavorable environmental conditions (temperature, moisture, limited nutrients) and is genetically programmed and reversible. Even in a dormant state, MAP infectivity of has been described (Lamont et al., 2014). Further research is needed to elucidate whether degradation or dormancy led to detectable MAP DNA when viable MAP was significantly reduced after mesophilic fermentation.

In conclusion, mesophilic fermentation in BP does lead to a substantial reduction of viable MAP, compared with unfermented slurry. In addition, composting of the digestate for several months probably reduces viable MAP even further. The findings presented here support those of earlier studies, that mesophilic BP fermentation of slurry or manure from MAP-positive cattle leads to reduced contamination of agricultural land with MAP when such slurry or manure is used as fertilizer. Therefore, mesophilic fermentation is not only a useful tool to convert cattle waste into biogas and a nutrient-rich fertilizer; it may also contribute to MAP control within and between herds.

\section{ACKNOWLEDGMENTS}

The authors thank the dairy producers who participated in this study, the laboratory staff, and the veterinarians of the Thuringian Animal Health Service, who were involved in sample collection. The authors furthermore gratefully acknowledge financial support by the Thuringian Dairy Industry Association (Landesvereinigung Thüringer Milch e.V., Erfurt, Germany).

\section{REFERENCES}

Collins, M. T., K. B. Kenefick, D. C. Socket, R. S. Lambrecht, J. McDonald, and J. B. Jorgensen. 1990. Radiometric detection of $M y$ cobacterium paratuberculosis by using filter-concentrated bovine fecal specimens. J. Clin. Microbiol. 28:2514-2519.

Donaghy, J. A., M. T. Rowea, J. L. W. Rademaker, P. Hammer, L. Herman, V. De Jonghe, B. Blanchard, K. Duhem, and E. Vindel. 2008. An inter-laboratory ring trial for the detection and isolation of Mycobacterium avium ssp. paratuberculosis from raw milk artificially contaminated with naturally infected faeces. Food Microbiol. $25: 128-135$.

Donat, K. 2017. The Thuringian bovine paratuberculosis control programme-Results and experiences. Berl. Munch. Tierärztl. 130:42-49. https://doi.org/10.2376/0005-9366-129-15129.

Donat, K., N. Hahn, T. Eisenberg, K. Schlez, H. Köhler, W. Wolter, M. Rohde, R. Pützschel, U. Rösler, K. Failing, and P. M. Zschöck. 2016. Within-herd prevalence thresholds for the detection of $M y$ cobacterium avium subspecies paratuberculosis-positive dairy herds using boot swabs and liquid manure samples. Epidemiol. Infect. 144:413-424. https://doi.org/10.1017/S0950268815000977.

Donat, K., U. Schau, and A. Soschinka. 2011. Identifizierung von mit Mycobacterium avium ssp. Paratuberculosis (MAP) infizierten Milchviehbeständen mithilfe von Umgebungskotproben. Berl. Munch. Tierarztl. 124:360-367. https://doi.org/10.2376/0005 -9366-124-360.

Doré, E., J. Paré, G. Côté, S. Buczinski, O. Labrecque, J. P. Roy, and G. Fecteau. 2012. Risk factors associated with transmission of Mycobacterium avium ssp. paratuberculosis to calves within dairy herd: A systematic review. J. Vet. Intern. Med. 26:32-45. https:// doi.org/10.1111/j.1939-1676.2011.00854.x.

Eisenberg, S. W. F., A. P. Koets, J. Hoeboer, M. Bouman, D. Heederik, and M. Nielen. 2010. Presence of Mycobacterium avium ssp. paratuberculosis in environmental dust samples on commercial dairy farms. Appl. Environ. Microbiol. 76:6310-6312. https://doi .org/10.1128/AEM.00998-10.

Elliott, G. N., R. L. Hough, L. M. Avery, C. A. Maltin, and C. D. Campbell. 2015. Environmental risk factors in the incidence of Johne's disease. Crit. Rev. Microbiol. 41:488-507. https://doi.org/ 10.3109/1040841X.2013.867830.

Englund, S., A. Ballagi-Pordany, G. Bölske, and K. E. Johansson. 1999. Single PCR and nested PCR with a mimic molecule for 
detection of Mycobacterium avium ssp. paratuberculosis. Diagn. Microbiol. Infect. Dis. 33:163-171.

Eppleston, J., D. J. Begg, N. K. Dhand, B. Watt, and R. J. Whittington. 2014. Environmental survival of Mycobacterium avium ssp. paratuberculosis in different climatic zones of eastern Australia. Appl. Environ. Microbiol. 80:2337-2342. https://doi.org/10.1128/ AEM.03630-13.

Fecteau, M. E., E. Hovingh, R. H. Whitlock, and R. W. Sweeney. 2013. Persistence of Mycobacterium avium ssp. paratuberculosis in soil, crops, and ensiled feed following manure spreading on infected farms. Can. Vet. J. 54:1083-1085.

Fecteau, M. E., R. Whitlock, C. D. Buergelt, and R. W. Sweeney. 2010. Exposure of young dairy cattle to Mycobacterium avium ssp. paratuberculosis (MAP) through intensive grazing of contaminated pastures in a herd positive for Johne's disease. Can. Vet. J. 51:198-200.

Federal Diet. 2000. Law for Prioritization of Renewable Energies [in German]. Bundesgesetzblatt 2000 Teil 1 Nr. 13. p. 305-309. Accessed Oct. 23, 2017. https://dejure.org/BGBl/2000/BGBl._I_S. -305.

Federal Diet. 2011. Act reforming the stimulation of electricity generation from renewable energies. Bundesgesetzblatt Teil I:1634-1678.

Federal Ministry for Food and Agriculture. 2014. Recommendations on Hygienic Demands on Keeping Ruminants [in German]. Bundesanzeiger, Amtlicher Teil 01.08.2014 B1. Accessed Oct. 23, 2017. https://tsis.fli.de/GlobalTemp/201905041657431356.pdf.

Friedrich-Loeffler-Institut. 2015. Manual of Official Methods. Friedrich-Loeffler-Institut, Bundesforschungsinstitut für Tiergesundheit. Accessed Oct. 20, 2015. https://www.openagrar.de/receive/ openagrar_mods_00006124.

Gelman, A. 2008. Scaling regression inputs by dividing by two standard deviations. Stat. Med. 27:2865-2873. https://doi.org/10 $.1002 / \operatorname{sim} .3107$.

Gelman, A., A. Jakulin, M. G. Pittau, and Y. S. Su. 2008. A weakly informative default prior distribution for logistic and other regression models. Ann. Appl. Stat. 4:1360-1383.

Grant, I. R., E. I. Hitchings, A. McCartney, F. Ferguson, and M. T. Rowe. 2002. Effect of commercial-scale high-temperature, shorttime pasteurization on the viability of Mycobacterium paratuberculosis in naturally infected cows' milk. Appl. Environ. Microbiol. 68:602-607. https://doi.org/10.1128/AEM.68.2.602-607.2002.

Grewal, S. K., S. Rajeev, A. Sreevatsan, and F. C. Michel. 2006. Persistence of Mycobacterium avium ssp. paratuberculosis and other zoonotic pathogens during simulated composting, manure packing, and liquid storage of dairy manure. Appl. Environ. Microbiol. 72:565-574. https://doi.org/10.1128/AEM.72.1.565-574.2006.

Jørgensen, J. B. 1977. Survival of Mycobacterium paratuberculosis in slurry. Nord. Vet. Med. 29:267-270.

Katayama, N., C. Tanaka, T. Fujita, Y. Saitou, S. Suzuki, and E. Onouchi. 2000. Effect of ensilage on inactivation of M. avium ssp. paratuberculosis. Grassl. Sci. 46:282-288. (Abstr.)

Katayama, N., C. Tanaka, T. Fujita, T. Suzuki, S. Watanabe, and S. Suzuki. 2001. Effects of silage fermentation and ammonia treatment on activity of Mycobacterium avium ssp. paratuberculosis. Grassl. Sci. 47:296-299. (Abstr).

Lamont, E. A., A. M. Talaat, P. M. Coussens, J. P. Bannantine, Y. T. Grohn, R. Katani, L. L. Li, V. Kapur, and S. Sreevatsan. 2014 Screening of Mycobacterium avium ssp. paratuberculosis mutants for attenuation in a bovine monocyte-derived macrophage model Front Cell Infect. Microbiol. 4:87-93. https://doi.org/10.3389/ fcimb.2014.00087.

Larsen, A. B., R. S. Merkal, and T. H. Vardaman. 1956. Survival time of Mycobacterium paratuberculosis. Am. J. Vet. Res. 17:549-551.

Lavers, C. J., A. L. B. McKenna, I. R. Dohoo, H. W. Barkema, and G. P. Keefe. 2013. Evaluation of environmental fecal culture for $M y$ cobacterium avium subspecies paratuberculosis detection in dairy herds and association with apparent within-herd prevalence. Can. Vet. J. 54:1053-1060.
Lombard, J. E. 2011. Epidemiology and economics of paratuberculosis. Vet. Clin. North Am. Food Anim. Pract. 27:525-535. https://doi .org/10.1016/j.cvfa.2011.07.012.

Mazzone, P., S. Corneli, A. Di Paolo, C. Maresca, A. Felici, M. Biagetti, M. Ciullo, C. Sebastiani, G. Pezzotti, S. Leo, M. Ricchi, and N. Arrigoni. 2018. Survival of Mycobacterium avium ssp. paratuberculosis (MAP) in the intermediate and final digestion products of biogas plants. J. Appl. Microbiol. 125:36-44. https://doi.org/10 $.1111 /$ jam. 13762

Olsen, J. E., J. B. Jørgensen, and P. Nansen. 1985. On the reduction of Mycobacterium paratuberculosis in bovine slurry subjected to batch mesophilic or thermophilic anaerobic digestion. Agric. Wastes 13:273-280.

Olsen, J. E., and H. E. Larsen. 1987. Bacterial decimation times in anaerobic digestion of animal slurries. Biol. Wastes 21:153-168.

Plummer, M. 2016. JAGS - Just Another Gibbs Sampler. Retrieved from http://mcmc-jags.sourceforge.net/.

Plym-Forshell, L. 1995. Survival of salmonellas and Ascaris suum eggs in a thermophilic biogas plant. Acta Vet. Scand. 36:79-85.

Pozzato, N., J. Gwozdz, M. Gastaldellia, K. Capello, C. Dal Ben, and E. Stefania. 2011. Evaluation of a rapid and inexpensive liquid culture system for the detection of Mycobacterium avium ssp. paratuberculosis in bovine faeces. J. Microbiol. Methods 84:413-417. https://doi.org/10.1016/j.mimet.2011.01.019.

Pribylova, R., I. Slana, M. Kaevska, J. Lamka, V. Babak, J. Jandak, and I. Pavlik. 2011. Soil and plant contamination with Mycobacterium avium ssp. paratuberculosis after exposure to naturally contaminated mouflon feces. Curr. Microbiol. 62:1405-1410. https:// doi.org/10.1007/s00284-011-9875-7.

R Core Team. 2016. R: A Language and Environment for Statistical Computing. R Foundation for Statistical Computing, Vienna, Austria. Accessed Jul. 19, 2016. https://www.R-project.org.

Reinhold, G. 2017. Substrateinsatz. Pages 16-21 in Projekt-Nr. 96.08 Abschlußbericht: Integration der Biogaserzeugung in die Landwirtschaft Thüringens [Article in German]. Accessed Jan. 15, 2019. http://www.tll.de/www/daten/pflanzenproduktion/nawaro/ nawaro_news/99_08_Biogas_ges.pdf.

Salgado, M., M. T. Collins, F. Salazar, J. Kruze, G. Bölske, R. Söderlund, R. Juste, I. A. Sevilla, F. Biet, F. Troncose, and M. Alfaro. 2011. Fate of Mycobacterium avium ssp. paratuberculosis after application of contaminated dairy cattle manure to agricultural soils. Appl. Environ. Microbiol. 77:2122-2129. https://doi.org/10.1128/ AEM.02103-10.

Slana, I., R. Pribylova, A. Kralova, and I. Pavlik. 2011. Persistence of Mycobacterium avium ssp. paratuberculosis at a farm-scale biogas plant supplied with manure from paratuberculosis-affected dairy cattle. Appl. Environ. Microbiol. 77:3115-3119. https://doi.org/10 .1128/AEM.02407-10.

Spiegelhalter, D., N. Best, B. Carlin, and A. van der Linde. 2002. Bayesian measures of model complexity and fit (with discussion). J. R. Stat. Soc. B 64:583-639.

Whittington, R. J., I. Marsh, M. J. Turner, S. McAllister, E. Choy, G. J. Eamens, D. J. Marshall, and S. Ottaawy. 1998. Rapid detection of Mycobacterium paratuberculosis in clinical samples from ruminants and in spiked environmental samples by modified BACTEC $12 \mathrm{~B}$ radiometric culture and direct confirmation by IS900 PCR. J. Clin. Microbiol. 36:701-707.

Whittington, R. J., D. J. Marshall, P. J. Nicholls, I. B. Marsh, and L. A. Reddacliff. 2004. Survival and dormancy of Mycobacterium avium ssp. paratuberculosis in the environment. Appl. Environ. Microbiol. 70:2989-3004. https://doi.org/10.1128/AEM.70.5.2989 -3004.2004 .

Wolf, R., K. Donat, J. L. Khol, H. W. Barkema, J. Kastelic, and P. Wagner. 2017. Detection of Mycobacterium avium subspecies paratuberculosis infected cattle herds using environmental samples: A systematic review. Berl. Munch. Tierärztl. 130:4-12. https://doi .org/10.2376/0005-9366-16023. 